\title{
EFEITO DAS CONDIÇÕES DE COLHEITA, PRÉ-PROCESSAMENTO E ARMAZENAMENTO NA QUALIDADE DO MILHO-PIPOCA ${ }^{1}$
}

\author{
SOLENIR RUFFATO ${ }^{2}$, PAULO CÉSAR CORRÊA ${ }^{3}$, JOSÉ HELVECIO MARTINS ${ }^{4}$, \\ BÁRBARA HELIODORA MACHADO MANTOVANI ${ }^{5}$ e JADIR NOGUEIRA DA SILVA ${ }^{6}$
}

\begin{abstract}
RESUMO - Com o objetivo de identificar parâmetros de decréscimos de qualidade de milho-pipoca, foram avaliados os efeitos dos métodos de colheita e debulha de grãos, dos teores de umidade inicial, da temperatura do ar de secagem e do tempo de armazenamento sobre a capacidade de expansão das cultivares Zélia e CMS 43. A colheita foi realizada quando ambas as cultivares de milho-pipoca atingiram o teor de umidade de $19 \%$ b.u. e, posteriormente, $15 \%$ b.u. Foram utilizadas a colheita e debulha manuais e a colheita mecânica com diferentes velocidades do cilindro debulhador. O produto foi submetido à secagem artificial em camada fina. Periodicamente, realizou-se o teste-padrão de qualidade relativo à capacidade de expansão do milho-pipoca. A qualidade do grão foi afetada significativamente pela colheita mecânica e pelo aumento da temperatura do ar de secagem mas não foi reduzida durante o armazenamento. Os melhores valores de capacidade de expansão, com relação à maioria dos tratamentos, foram obtidos depois de 270 dias de armazenamento. O milho-pipoca da cultivar Zélia apresentouse com qualidade comercial superior à da cultivar CMS 43, porém é necessário salientar que esta última encontra-se ainda em fase de desenvolvimento e melhoramento genético.
\end{abstract}

Termos para indexação: umidade do grão, temperatura de secagem, tempo de armazenamento, capacidade de expansão.

\section{EFFECTS OF HARVESTING CONDITIONS, PRE-PROCESSING AND STORAGE ON THE QUALITY OF POPCORN}

\begin{abstract}
Aiming to identify parameters of popcorn quality decreases, the effects of harvest and shelling methods, initial moisture contents, drying air temperature and storage time on the expansion capacity of the Zélia and CMS 43 cultivars were evaluated. The harvest was performed when both popcorn varieties reached moisture contents of 19\% w.b. and, further, 15\% w.b. Manual harvest and shelling and mechanic harvest with different speeds of the shelling cylinder were used. The product was submitted to artificial drying process in thin layers and also to natural drying. Periodically a quality pattern-test related to the popcorn expansion capacity was performed. The grain quality was significantly affected by mechanical harvest and by increase in the drying air temperature; there was no decrease on the physiological quality of the popcorn during the storage; the best values of expansion capacity, for most of the treatments, were obtained after 270 days of storage. The popcorn of Zélia variety showed superior commercial quality compared to the variety CMS 43 . However, it is necessary to stress the fact that the latter is still in stage of development and genetic breeding.
\end{abstract}

Index terms: grain moisture, drying temperature, storage period, expansion capacity.

${ }^{1}$ Aceito para publicação em 25 de maio de 1999. Extraído da Tese de Mestrado apresentada pelo primeiro autor à Universidade Federal de Viçosa (UFV).

${ }^{2}$ Eng. Agríc., M.Sc., Dep. de Engenharia Agrícola, UFV, CEP 36570-000 Viçosa, MG. E-mail: sruffato@alunos.ufv.br

${ }^{3}$ Eng. Agrôn., D.Sc., Dep. de Engenharia Agrícola, UFV. Bolsista do CNPq. E-mail: copace@mail.ufv.br

${ }^{4}$ Eng. Agríc., Ph.D., Dep. de Engenharia Agrícola, UFV. Bolsista do CNPq. E-mail: jmartins@mail.ufv.br

${ }^{5}$ Eng. Agríc., Ph.D., Embrapa-Centro Nacional de Pesquisa de Milho e Sorgo (CNPMS), Caixa Postal 151, CEP 35701-970 Sete Lagoas, MG.

${ }^{6}$ Físico, Ph.D., Dep. de Engenharia Agrícola, UFV. Bolsista do CNPq. E-mail: jadir@mail.ufv.br

\section{INTRODUÇÃO}

A cultura do milho-pipoca é típica do continente americano e utilizada exclusivamente para o consumo humano. Por isso, tem-se observado cada vez maior preocupação com a sua qualidade. Constituise numa boa opção econômica para os produtores, e sua venda gera divisas em todo o mundo.

No Brasil, em razão da chegada de pipocas importadas dos Estados Unidos e também devido ao lançamento recente de variedades nacionais para uso em fornos de microondas, este mercado encontra-se 
em expansão. Como é o mercado que determina os rumos da agricultura, o cultivo do milho-pipoca tende a expandir-se. Para isso, conta com alguns fatores favoráveis: a cultura pode ser totalmente mecanizada, e é pouco suscetível ao ataque de pragas e doenças no campo, e seus preços não são controlados pelo governo. Além disso, seu preço tem sido no mínimo três vezes superior ao do milho comum (Milho-pipoca, 1993). Em virtude disso, a qualidade do milho-pipoca tem melhorado gradualmente nos últimos anos, embora não existam padrões oficiais de qualidade para este e para a maioria dos produtos vegetais produzidos no País.

A capacidade de expansão (CE) é calculada pela relação entre o volume de pipoca obtido e o volume de grãos utilizados, e constitui o principal parâmetro de qualidade do milho-pipoca. Zinsly \& Machado (1978) explicam que a capacidade que tem o milho-pipoca de expandir-se é devida à resistência do seu pericarpo, associada à presença, no grão, de óleo e umidade. Segundo Silva et al. (1993), quando aquecido, o amido do milho-pipoca expande-se, aumentando gradualmente a pressão interna do grão até o momento em que ocorre a explosão, quando a temperatura chega a, aproximadamente, $180^{\circ} \mathrm{C}$ e a pressão atinge $930,8 \mathrm{kPa}$. Em temperaturas inferiores a $177^{\circ} \mathrm{C}$, a proporção de grãos que se expande diminui acentuadamente.

A CE do milho-pipoca está condicionada tanto a fatores genéticos quanto a não-genéticos, como as condições de desenvolvimento em campo, de colheita e do pré-processamento.

O teor de umidade na ocasião da colheita apresenta uma influência bastante significativa na qualidade do milho-pipoca colhido mecanicamente. Para assegurar condições ideais de armazenamento, o teor de umidade deve ser reduzido por meio de secagem artificial. A secagem, dentre outras operações pós-colheita, tem sido considerada um importante fator que influencia a qualidade dos grãos. Dessa forma, há a necessidade de maiores informações a respeito do efeito prejudicial da secagem sobre a qualidade do milho-pipoca, o que poderá afetar diretamente a sua capacidade de expansão.

Teores de umidade entre $13 \%$ e $15 \%$ b.u. parecem ser os mais favoráveis para um ótimo rendimento do milho-pipoca. Este rendimento é raramente obtido se o teor de umidade for inferior a $12 \%$ b.u. ou superior a $16 \%$ b.u. (Stewart, 1923).

Segundo White et al. (1981), a secagem do milho-pipoca é mais crítica do que a secagem de milho comum, pois pode ocorrer a redução na sua capacidade de expansão em face do aumento da temperatura de secagem e do teor de umidade inicial dos grãos (na ocasião da colheita). Segundo esses mesmos autores, Bemis \& Huelsen em 1955 afirmaram que, caso a secagem ocorra de forma rápida (em altas temperaturas) e seguida de um resfriamento rápido, podem ocorrer trincas internas no endosperma dos grãos.

A formação de trincas nos grãos é, em geral, influenciada por diversos fatores. Gunasekaran et al. (1985) citam, como fatores que podem contribuir para o desenvolvimento de trincas, os teores de umidade inicial e final dos grãos na secagem, o método de secagem, a vazão, a temperatura do ar de secagem e o tipo de milho.

Pela literatura consultada, pode-se inferir que o teor de umidade dos grãos, as condições do pericarpo e endosperma, o método de secagem, a temperatura do pipocador, são os principais fatores que afetam a capacidade de expansão do milhopipoca.

Todas as informações indicam que não há redução da capacidade de expansão do milho-pipoca quando é armazenado adequadamente e protegido da infestação por insetos.

Há uma demanda cada vez maior de alimentos de boa qualidade, um crescente consumo de milhopipoca no País e escassez de informações sobre a cultura, beneficiamento, armazenamento e comercialização desse cereal. O objetivo deste trabalho foi avaliar os efeitos do teor de umidade inicial dos grãos (na ocasião da colheita), da velocidade do cilindro da colhedora, da temperatura do ar de secagem e do período de armazenamento, sobre a capacidade de expansão de milho-pipoca de duas cultivares.

\section{MATERIAL E MÉTODOS}

O presente trabalho foi realizado na Embrapa-Centro Nacional de Pesquisa de Milho e Sorgo (CNPMS), localizada em Sete Lagoas, MG, e no Laboratório de PréProcessamento de Produtos Vegetais do Departamento de 
Engenharia Agrícola da Universidade Federal de Viçosa. Foram utilizadas duas cultivares de milho-pipoca (Zélia e CMS 43).

Ambas as cultivares de milho-pipoca foram colhidas com teores de umidade inicial de $19 \%$ b.u. e, posteriormente, $15 \%$ b.u., pelos seguintes métodos: colheita mecânica com diferentes velocidades do cilindro debulhador $(500$, 600 e $700 \mathrm{rpm}$ ) e colheita manual com debulha manual. Os teores de umidade foram determinados pelo método-padrão de estufa $\left(105^{\circ} \mathrm{C} \pm 3^{\circ} \mathrm{C}\right.$, durante 24 horas), com três repetições, de acordo com as Regras para Análise de Sementes (Brasil, 1992). Para manutenção da umidade do produto, as amostras foram colocadas em embalagens de polietileno de baixa densidade e armazenadas em um refrigerador à temperatura de, aproximadamente, $4^{\circ} \mathrm{C}$.

Antes da operação de secagem, as amostras embaladas foram retiradas do refrigerador e deixadas expostas à temperatura ambiente por doze horas, de forma a atingir o equilíbrio térmico. Realizou-se novamente a determinação do teor de umidade pelo método-padrão de estufa.

A secagem foi feita com um secador de laboratório em camada fina, com controle da temperatura e vazão do ar. A velocidade do ar de secagem foi mantida constante em $1 \mathrm{~m} \mathrm{~s}^{-1}$ e monitorada por um anemômetro digital de lâminas rotativas. O fluxo de ar era proporcionado por um ventilador axial que conduzia o ar até o plênum, de onde fluía para três câmaras individualizadas com bandejas de fundo telado e removíveis. Utilizaram-se temperaturas do ar de secagem de $40^{\circ} \mathrm{C}, 50^{\circ} \mathrm{C}$ e $60^{\circ} \mathrm{C}$, medidas com um termômetro de mercúrio instalado logo abaixo da camada de grãos. A temperatura e a umidade relativa do ar foram registradas utilizando um termoigrógrafo. O final da secagem era determinado quando as amostras atingiam um teor de umidade final preestabelecido de $12 \pm 1 \%$ b.u. Utilizou-se uma balança semi-analítica com precisão de $\pm 0,01 \mathrm{~g}$, para o acompanhamento da secagem, pesando-se as amostras a cada intervalo de cinco minutos, para secagem com ar aquecido, e a cada intervalo de 30 minutos, para secagem com ar ambiente.

Depois de secas, as amostras foram mantidas em condições ambientes até atingirem equilíbrio térmico, quando, então, foram subdivididas em amostras de $30 \mathrm{~mL}$, e este volume foi medido por uma proveta de $50 \mathrm{~mL}$. Essas amostras foram embaladas em sacos de polipropileno, selados com seladora elétrica, e devidamente identificados. As três repetições da mesma amostra foram reunidas e colocadas em sacos de polietileno também selados e armazenadas em caixas de papelão, onde ficaram até o momento do teste de expansão, que foi realizado periodicamente, sendo um imediatamente depois da secagem, e os outros, em intervalos de três meses, totalizando cinco testes de expansão e doze meses de armazenamento.
Foi utilizada para o teste de expansão, uma máquina elétrica protótipo, com controle de temperatura, desenvolvida pela Embrapa-Centro Nacional de Pesquisa e Desenvolvimento de Instrumentação Agropecuária, em São Carlos, SP. As amostras de $30 \mathrm{~mL}$ de milho-pipoca foram submetidas a uma temperatura de $237^{\circ} \mathrm{C}$ por quatro minutos, sob constante agitação. Em seguida, coletava-se a pipoca resultante e media-se o seu volume em uma proveta de $1.000 \mathrm{~mL}$.

A capacidade de expansão era obtida pela razão entre o volume de pipoca expandida e o volume inicial de grãos.

\section{RESULTADOS E DISCUSSÃO}

As médias dos tratamentos foram comparadas pelo teste de agrupamento de Scott Knott a 5\% de probabilidade (Scott \& Knott, 1974), em relação às cultivares Zélia e CMS 43, respectivamente.

Observa-se, na Tabela 1, que o melhor resultado de capacidade de expansão da cultivar Zélia foi obtido do milho-pipoca colhido com teor de umidade de $19 \%$ b.u., debulhado manualmente e secado a $40^{\circ} \mathrm{C}$.

Observa-se, também, que a qualidade do milhopipoca diminui com o processo de colheita mecânica quanto aos dois teores de umidade iniciais e em qualquer condição de secagem, embora as velocidades do cilindro debulhador não tenham influenciado significativamente sua capacidade de expansão. Esses resultados são semelhantes aos obtidos por Lien et al. (1976), que verificaram uma queda na capacidade de expansão de até $23 \%$ na colheita mecânica em comparação com a colheita manual.

Nota-se, também, na Tabela 1, que o aumento da temperatura provocou redução significativa dos valores de capacidade de expansão do milho-pipoca colhido a $19 \%$ e $15 \%$ b.u. Porém, no tocante a este último teor de umidade, as reduções da capacidade de expansão nas temperaturas de secagem de 50 e $60^{\circ} \mathrm{C}$ foram estatisticamente iguais.

Na Tabela 2, estão relacionados os resultados de capacidade de expansão do milho-pipoca da cultivar CMS 43. Observa-se que esta cultivar apresenta comportamento semelhante ao da cultivar Zélia, porém os valores médios de capacidade de expansão foram menores na maioria dos tratamentos. Segundo in- 
formações obtidas na Embrapa-CNPMS, onde esta variedade está sendo desenvolvida, diversos trabalhos genéticos estão em andamento com a finalidade de melhorar suas características.

A temperatura de secagem de $40^{\circ} \mathrm{C}$ proporcionou os melhores resultados de capacidade de expansão no que tange a esta cultivar, independentemente do teor de umidade com o qual o produto foi colhido.

Em todos os tratamentos, os valores de capacidade de expansão diferiram estatisticamente da colheita manual em relação à mecânica. No entanto, não houve efeito significativo da velocidade do cilindro debulhador sobre os resultados de capacidade de expansão em relação a um mesmo teor de umidade inicial e mesma temperatura do ar de secagem.

O milho-pipoca da cultivar CMS 43 apresentou melhores resultados de capacidade de expansão, quando colhido manualmente, com teor de umidade de $19 \%$ b.u., e exposto à temperatura de secagem de $40^{\circ} \mathrm{C}(\mathrm{CE}=18,94)$, ou quando foi colhido com um teor de umidade de $15 \%$ b.u., manualmente ou com velocidade do cilindro debulhador de $600 \mathrm{rpm}$, e secado à temperatura de $40^{\circ} \mathrm{C}$ ( $\mathrm{CE}=20,77$ e 16,77, respectivamente).

É importante ressaltar que no Brasil, as normas específicas de classificação de qualidade de milhopipoca, em função da capacidade de expansão, estão em fase de preparo.

TABELA 1. Valores médios da capacidade de expansão do milho-pipoca, cultivar Zélia, colhido com dois teores de umidade e submetido a quatro métodos de debulha e três temperaturas do ar de secagem 1 .

\begin{tabular}{lccccccc}
\hline Método de & $\begin{array}{c}\text { Velocidade } \\
\text { debulha }\end{array}$ & \multicolumn{5}{c}{ Teor de umidade inicial na colheita (\% b.u.) / temperatura do ar de secagem $\left({ }^{\circ} \mathrm{C}\right)$} \\
\cline { 3 - 7 } & $\begin{array}{c}\text { do cilindro } \\
\text { debulhador (rpm) }\end{array}$ & $19 / 40$ & $19 / 50$ & $19 / 60$ & $15 / 40$ & $15 / 50$ & $15 / 60$ \\
\hline Manual & - & $25,16 \mathrm{a}$ & $22,28 \mathrm{~b}$ & $20,17 \mathrm{c}$ & $24,16 \mathrm{a}$ & $22,66 \mathrm{~b}$ & $21,49 \mathrm{~b}$ \\
Mecânica & 500 & $21,44 \mathrm{~b}$ & $18,94 \mathrm{c}$ & $15,78 \mathrm{~d}$ & $21,11 \mathrm{~b}$ & $20,38 \mathrm{c}$ & $19,90 \mathrm{c}$ \\
Mecânica & 600 & $21,44 \mathrm{~b}$ & $18,66 \mathrm{c}$ & $17,98 \mathrm{~d}$ & $23,11 \mathrm{~b}$ & $21,28 \mathrm{~b}$ & $20,16 \mathrm{c}$ \\
Mecânica & 700 & $20,16 \mathrm{c}$ & $18,22 \mathrm{~d}$ & $16,94 \mathrm{~d}$ & $21,94 \mathrm{~b}$ & $20,11 \mathrm{c}$ & $19,11 \mathrm{c}$ \\
\hline
\end{tabular}
Scott Knot.

TABELA 2. Valores médios da capacidade de expansão do milho-pipoca, cultivar CMS 43, colhido com dois teores de umidade e submetido a quatro métodos de debulha e quatro temperaturas do ar de secagem 1 .

\begin{tabular}{lccccccc}
\hline Método de & $\begin{array}{c}\text { Velocidade } \\
\text { debulha }\end{array}$ & \multicolumn{5}{c}{ Teor de umidade inicial na colheita $(\%$ b.u. $) /$ temperatura do ar de secagem $\left({ }^{\circ} \mathrm{C}\right)$} \\
\cline { 3 - 7 } & $\begin{array}{c}\text { do cilindro } \\
\text { debulhador }(\mathrm{rpm})\end{array}$ & $19 / 40$ & $19 / 50$ & $19 / 60$ & $15 / 40$ & $15 / 50$ & $15 / 60$ \\
\hline Manual & - & $18,94 \mathrm{a}$ & $15,50 \mathrm{~b}$ & $13,39 \mathrm{c}$ & $20,77 \mathrm{a}$ & $15,66 \mathrm{~b}$ & $15,28 \mathrm{~b}$ \\
Mecânica & 500 & $14,22 \mathrm{c}$ & $12,16 \mathrm{~d}$ & $10,33 \mathrm{~d}$ & $16,77 \mathrm{~b}$ & $14,33 \mathrm{c}$ & $12,66 \mathrm{c}$ \\
Mecânica & 600 & $15,39 \mathrm{~b}$ & $12,22 \mathrm{~d}$ & $11,00 \mathrm{~d}$ & $16,77 \mathrm{~b}$ & $14,50 \mathrm{c}$ & $13,78 \mathrm{c}$ \\
Mecânica & 700 & $14,00 \mathrm{c}$ & $10,77 \mathrm{~d}$ & $8,83 \mathrm{~d}$ & $15,33 \mathrm{~b}$ & $11,50 \mathrm{~d}$ & $11,55 \mathrm{~d}$ \\
\hline
\end{tabular}

${ }^{1}$ As médias seguidas de uma mesma letra, nas colunas e nas linhas, não diferem estatisticamente entre si, a $5 \%$ de probabilidade, pelo teste de Scott Knot. 
Em geral, o milho-pipoca colhido com teor de umidade de $15 \%$ b.u. e secado a $50^{\circ} \mathrm{C}$ e $60^{\circ} \mathrm{C}$ apresenta maior capacidade de expansão, em comparação com o milho-pipoca colhido com teor de umidade de $19 \%$ b.u. e secado nas mesmas condições. Conclusões similares obtiveram Lien \& Haugh (1975), que indicam teor de umidade de colheita abaixo de $18 \%$ b.u. para se obter a máxima capacidade de expansão.

Na Tabela 3 estão relacionadas as equações, ajustadas por meio de regressão, e os respectivos coeficientes de determinação quanto à capacidade de expansão, referentes às cultivares, teores de umida- de inicial do produto (na colheita), e velocidade do cilindro debulhador, em função da temperatura do ar de secagem e do tempo de armazenamento.

As equações 3, 4, 9, 11, 12, 14 e 16 da Tabela 3, obtidas com relação aos devidos tratamentos, mostram uma mesma tendência, ou seja, a capacidade de expansão é inversamente proporcional ao aumento da temperatura do ar de secagem e diretamente proporcional ao tempo de armazenamento.

Dessa forma, conclui-se que não houve efeito latente dos tratamentos e das condições em que o trabalho foi desenvolvido sobre a capacidade de

TABELA 3. Equações de regressão, ajustadas para a capacidade de expansão $(\hat{Y})$, e coeficiente de determinação das cultivares Zélia e CMS 43, teor de umidade do produto na colheita e velocidade do cilindro debulhador, em virtude da temperatura do ar de secagem (T), expressa em ${ }^{\circ} \mathrm{C}$, e do tempo de armazenamento (TPO), expresso em dias.

\begin{tabular}{|c|c|c|c|}
\hline $\mathrm{N}^{\mathrm{0}}$ & Combinações $^{1}$ & Equações ajustadas & $\mathrm{R}^{2}$ \\
\hline 1 & C1U1V1 & $\hat{Y}=25,09860+0,17623 * \mathrm{~T}+0,00137 * * * \mathrm{TPO}-0,00428 * * \mathrm{~T}^{2}$ & 0,8972 \\
\hline 2 & C1U1V2 & $\hat{Y}=29,54910-0,21399 * * \mathrm{~T}-0,01104 * \mathrm{TPO}+0,000033 * \mathrm{TPO}^{2}$ & 0,8669 \\
\hline 3 & C1U1V3 & $\hat{Y}=27,74920-0,16518^{* * \mathrm{~T}}+0,00419^{* * \mathrm{TPO}}$ & 0,9180 \\
\hline 4 & C1U1V4 & $\hat{Y}=28,45410-0,19731^{* *} \mathrm{~T}+0,00203^{*} \mathrm{TPO}$ & 0,9276 \\
\hline 5 & C1U2V1 & $\hat{Y}=22,04360+0,19618 * \mathrm{~T}+0,02422 * * \mathrm{TPO}-0,00343^{* *} \mathrm{~T}^{2}-0,000037 * * \mathrm{TPO}^{2}$ & 0,9534 \\
\hline 6 & C1U2V2 & $\hat{Y}=24,80080-0,08463 * * \mathrm{~T}+0,02334 * * \mathrm{TPO}-0,000035^{*} \mathrm{TPO}^{2}$ & 0,7750 \\
\hline 7 & $\mathrm{C} 1 \mathrm{U} 2 \mathrm{~V} 3$ & $\hat{Y}=20,83380+0,13103 * \mathrm{~T}+0,02582 * * \mathrm{TPO}-0,00219 * * \mathrm{~T}^{2}-0,000044 * * \mathrm{TPO}^{2}$ & 0,9039 \\
\hline 8 & C1U2V4 & $\hat{Y}=26,44230-0,11966 * * \mathrm{~T}+0,02473 * * \mathrm{TPO}-0,000049 * * \mathrm{TPO}^{2}$ & 0,9057 \\
\hline 9 & C2U1V1 & $\hat{Y}=26,55760-0,21301 * * \mathrm{~T}+0,00140 * * * \mathrm{TPO}$ & 0,9221 \\
\hline 10 & $\mathrm{C} 2 \mathrm{U} 1 \mathrm{~V} 2$ & $\hat{Y}=25,68280-0,34838 * * \mathrm{~T}+0,01132 * * \mathrm{TPO}^{*} *+0,00155 * \mathrm{~T}^{2}-0,000028 * * \mathrm{TPO}^{2}$ & 0,9759 \\
\hline 11 & $\mathrm{C} 2 \mathrm{U} 1 \mathrm{~V} 3$ & $\hat{Y}=23,03830-0,21160 * * \mathrm{~T}+0,00112 * * *$ TPO & 0,9612 \\
\hline 12 & $\mathrm{C} 2 \mathrm{U} 1 \mathrm{~V} 4$ & $\hat{Y}=20,86270-0,18064 * * \mathrm{~T}+0,00371 * \mathrm{TPO}$ & 0,8721 \\
\hline 13 & $\mathrm{C} 2 \mathrm{U} 2 \mathrm{~V} 1$ & $\hat{Y}=25,88600-0,17442 * * \mathrm{~T}+0,01567 * * \mathrm{TPO}-0,000031 * \mathrm{TPO}^{2}$ & 0,8850 \\
\hline 14 & $\mathrm{C} 2 \mathrm{U} 2 \mathrm{~V} 2$ & $\hat{Y}=21,17000-0,12794 * * \mathrm{~T}+0,00589^{*} * \mathrm{TPO}$ & 0,8314 \\
\hline 15 & $\mathrm{C} 2 \mathrm{U} 2 \mathrm{~V} 3$ & $\hat{Y}_{=}=22,65040-0,15103 * * \mathrm{~T}+0,00771 * \mathrm{TPO}-0,000017 * \mathrm{TPO}^{2}$ & 0,9528 \\
\hline 16 & $\mathrm{C} 2 \mathrm{U} 2 \mathrm{~V} 4$ & 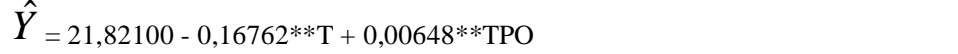 & 0,8911 \\
\hline
\end{tabular}

${ }^{1}$ C1 e C2: cultivares Zélia e CMS 43, respectivamente; U1 e U2: teor de umidade inicial do produto na colheita, $19 \%$ e $15 \%$ ( $\pm 1 \%$ b.u.), respectivamente; V1: colheita e debulha manuais; V2, V3 e V4: colheita e debulha mecânicas com velocidade do cilindro debulhador de 500, 600 e 700 rpm, respectivamente.

$*, * *, * * *$ e $* * * *$ significativo a $5 \%, 1 \%, 15 \%$ e $20 \%$, respectivamente, pelo teste t. 
expansão durante o armazenamento, por um período de 360 dias. Quanto aos outros tratamentos de ambas as cultivares, o comportamento foi semelhante, e houve uma tendência de acréscimo da capacidade de expansão no decorrer do tempo de armazenamento. De acordo com Zinsly \& Machado (1987), quando bem armazenadas, as sementes de milho-pipoca, conservam intacta sua capacidade de expansão por um período de 15 a 20 anos.

Para a representação gráfica (Figs. 1, 2, 3 e 4) das estimativas apresentadas na Tabela 3, selecionaram-se aleatoriamente dois tratamentos: cultivar Zélia, colhida com teor de umidade de $15 \%$ b.u. e debulhada a $500 \mathrm{rpm}$, e a cultivar CMS 43, colhida com teor de umidade $15 \%$ b.u. e debulhada manualmente.

Quando as estimativas foram representadas em face do tempo de armazenamento (Figs. 1 e 2), foram obtidos valores máximos de CE de 28,70 e 27,88 na cultivar Zélia (aproximadamente 335 dias de armazenamento) e na cultivar CMS 43 (aproximadamente 254 dias de armazenamento), respectivamente. Nota-se um crescimento gradual e constante da capacidade de expansão em todas as temperaturas do ar de secagem até o período de armazenamento de 270 dias, com tendência à manutenção ou ao decréscimo da capacidade de expansão a partir deste ponto, exceto na cultivar Zélia, colhida a $19 \%$ de umidade e debulhada a $500 \mathrm{rpm}$, em que a tendência de crescimento da capacidade de expansão permanece depois de transcorridos 360 dias de armazenamento, conforme pode ser observado pela equação $2 \mathrm{da}$ Tabela 3.

As estimativas de capacidade de expansão também foram representadas em face da temperatura do ar de secagem (Figs. 3 e 4), em ambas as cultivares e tratamentos correspondentes. Nesse caso, os maiores valores estimados da capacidade de expansão variaram de acordo com períodos de armazenamento de 270 a 360 dias. No entanto, demonstraram também a ausência do efeito latente dos tratamentos sobre a capacidade de expansão.

Normalmente, o tempo de validade de milhopipoca, tanto nacional como importado, varia de seis a doze meses. Assim, pode-se dizer que as

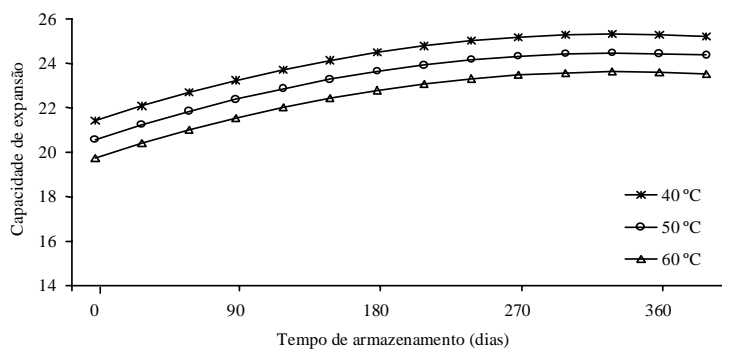

FIG. 1. Estimativa da capacidade de expansão da cultivar Zélia colhida a $15 \%$ b.u. de umidade e debulhada a 500 rpm, em função do tempo de armazenamento, com diferentes temperaturas do ar de secagem.

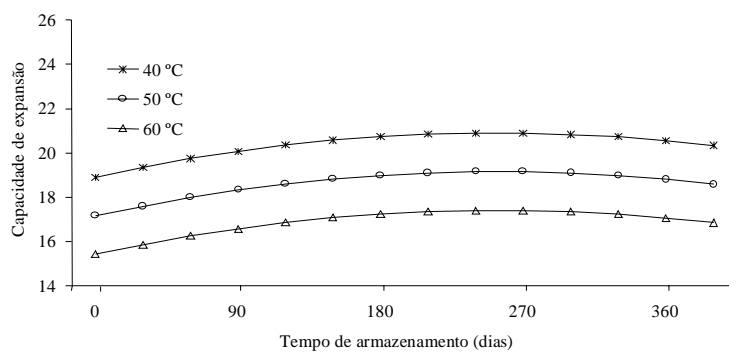

FIG. 2. Estimativa da capacidade de expansão da cultivar CMS 43 colhida a $15 \%$ b.u. de umidade e debulhada manualmente, em razão do tempo de armazenamento, com diferentes temperaturas do ar de secagem.

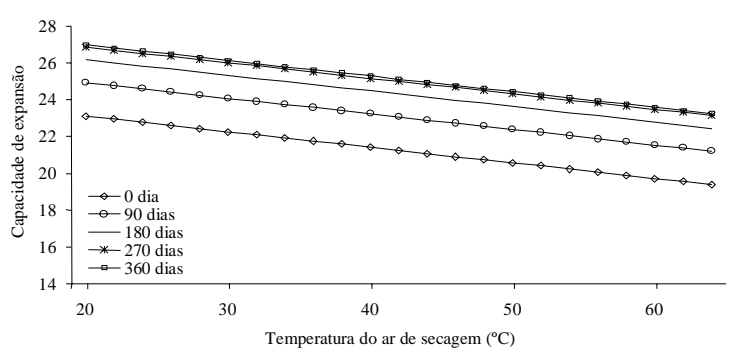

FIG. 3. Estimativa da capacidade de expansão da cultivar Zélia colhida a $15 \%$ b.u. de umidade e debulhada a $500 \mathrm{rpm}$, em virtude da temperatura do ar de secagem, com os respectivos tempos de armazenamento.

cultivares utilizadas no experimento mantiveram a sua qualidade dentro dessa faixa, ressaltando-se que a cultivar CMS 43 encontra-se ainda em fase de melhoramento genético. 


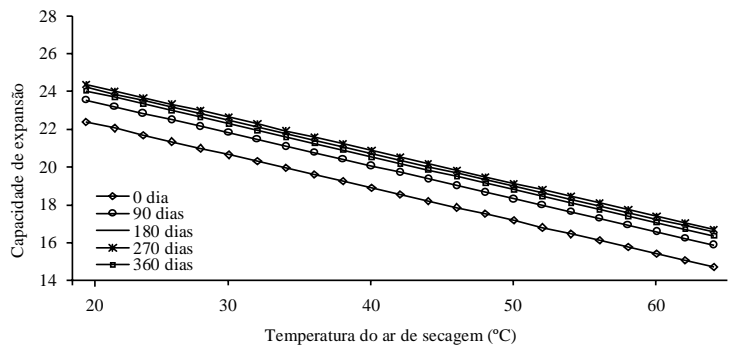

FIG. 4. Estimativa da capacidade de expansão da cultivar CMS 43 colhida a $15 \%$ b.u. de umidade e debulhada manualmente, em face da temperatura do ar de secagem, com os respectivos tempos de armazenamento.

No final do período de armazenamento, realizouse novamente a determinação do teor de umidade dos grãos de milho-pipoca, usando o método-padrão de estufa, quando se observou uma variação de $\pm 0,3$ ponto porcentual em relação ao teor de umidade inicial, antes do armazenamento (12\% b.u.).

\section{CONCLUSÕES}

1. Os efeitos da colheita mecânica sobre a capacidade de expansão são significativos em ambas as cultivares e teores de umidade iniciais, em qualquer condição de secagem empregada neste trabalho.

2. A colheita e a debulha manuais apresentam os melhores valores de capacidade de expansão.

3. Não há influência da velocidade do cilindro debulhador sobre a capacidade de expansão.

4. A qualidade do milho-pipoca é afetada significativamente pelo aumento da temperatura do ar de secagem.

5. Maiores rendimentos de capacidade de expansão são obtidos quando o milho-pipoca é colhido com $15 \%$ de umidade.

6. Não há efeito latente das condições de préprocessamento sobre a capacidade de expansão de ambas as cultivares.

7. A cultivar CMS 43 apresenta-se mais susceptível a danos ocasionados pela colheita mecânica e pelo processo de secagem que a cultivar Zélia.

\section{AGRADECIMENTOS}

À Fundação de Amparo à Pesquisa do Estado de Minas Gerais (FAPEMIG), e ao Conselho de Desenvolvimento Científico e Tecnológico (CNPq), pelo apoio financeiro para realização deste trabalho.

\section{REFERÊNCIAS}

BRASIL. Ministério da Agricultura e Reforma Agrária. Regras para análise de sementes. Brasília, 1992. $365 \mathrm{p}$.

GUNASEKARAN, S.; DESHPANDE, S.S.; PAULSEN, M.R.; SHOVE, G.C. Size characterization of stress cracks in corn kernels. Transactions of the ASAE, Saint Joseph, v.28, n.5, p.1668-1672, 1985.

LIEN, R.M.; HAUGH, C.G. The effect of field shelling on popcorn quality. Transactions of the ASAE, Saint Joseph, v.18, n.5, p.855-858, 1975.

LIEN, R.M.; HAUGH, C.G.; SILVER, M.J.; ASHMAN, R.B. Machine losses in field harvesting popcorn. Transactions of the ASAE, Saint Joseph, v.19, n.5, p.827-829, 1976.

MILHO-PIPOCA: cultura tem tudo para expandir-se. Informativo Coopercitrus, São Paulo, n.78, p.8-11, 1993.

SCOTT, A.J.; KNOTT, E.M. A cluster analysis method for grouping means in the analysis of variance. Biometrics, Alexandria, v.30, n.3, p.507-512, 1974.

SILVA, W.J. da; VIDAL, B.C.; MARTINS, M.E.Q.; VARGAS, H.; PEREIRA, A.C.; ZERBETTO, A What makes popcorn pop. Nature, London, v.362, n.6419, p.417, Apr.1993.

STEWART, F.C. The relation of moisture content and certain other factors to the popping of popcorn. Geneva, NY : The Station Under Authority of Cornell University, 1923. 70p. (Bulletin, 505).

WHITE, G.M.; ROSS I.J.; PONELEIT, C.G. Fully-exposed drying of popcorn. Transactions of the ASAE, Saint Joseph, v.24, n.2, p.466-468, 1981.

ZINSLY, J.R.; MACHADO, J.A. Milho-pipoca. In: PATERNIANI, E. (Coord.). Melhoramento do milho no Brasil. Piracicaba : Fundação Cargill, 1978. p.339-347.

ZINSLY, J.R.; MACHADO, J.A. Milho-pipoca. In: PATERNIANI, E.; VIEGAS, G.P. (Coords.). Melhoramento e produção de milho. Piracicaba : Fundação Cargill, 1987. p.411-450.

Pesq. agropec. bras., Brasília, v.35, n.3, p.591-597, mar. 2000 